\title{
Application and efficiency of vitrification and electrokinetic techniques in soil remediation
}

\author{
Wagner Luis Siveris', Guilherme Victor Vanzetto", Gabriel Immich"', Antônio Thomélv
}

\section{Abstract}

The improvement of remediation processes is necessary due to the impact caused by heavy metal ions and organic ionic compounds. Due to the lack of a universal method, several factors must be evaluated before choosing a technique. Vitrification and electrokinetics are soil remediation technologies that use the electrical potential to remediate. In vitrification the contaminant is immobilized in the soil, in electrokinetics, the contaminated material is separated from the soil. This bibliographical review had as main aim to approach vitrification and electrokinetics techniques in soils remediation. This review does not intend to exhaust the subject, but to approach the principles, application forms, advantages, disadvantages, efficiency, costs, and the application of the most cited methods in the literature. Vitrification has proven to be a safe technique, easy to apply and with good efficiency, however highly expansive. Electrokinetics proved to be more economically workable, with a variety of applications and with high efficiency.

Keywords: Contamination; Pollution; Review. 


\section{Introduction}

Soil is composed of variable amounts of minerals from the weathering of rocks plus the portion of organic matter from plant and animal remains. With a high population of microorganisms, the soils are generally dynamic and have their own characteristics, being formed by solid, liquid and gaseous phases (FONINI; ROJAS, 2006).

Pollutants or contaminants may be concentrated in the different phases of the soil, in saprolites, in regoliths, in sediments, in rocks, in groundwater or, in general, in saturated and unsaturated zones. The presence of any chemical in these sites, due to anthropic activities, and in concentrations that restrict the use of the method characterizes the contamination (CONAMA, 2009).

Soil contamination has generated concern among environmental agencies in several countries due to the large number of such areas (HU et al., 2006). The investments necessary for the remediation and decontamination of these sites are considerable, that way several techniques of soil remediation have been developed (USEPA, 2004).

The choice of decontamination method depends on several factors, since there is no universal method (LIU et al., 2004). There are methods that can be applied ex-situ, where the soil is removed, or in-situ, without soil removal. Moreover, the methods can be distinctive by the form of action in the contaminant, such as immobilization, separation, containment and degradation (BRAGATO, 2006).

The vitrification method is an in-situ soil remediation technique, where the contaminant undergoes the immobilization process. The procedure consists of forcing the electrical passage through electrodes until it fuses the contaminant in the place itself, forming a non-dangerous vitreous phase (PARNELL et al., 2001).

Electrokinetic remediation, also known as electromigration or electrocorrection, is an in-situ applied technique, the process consists in the application of a low intensity electric current through pairs of electrodes buried in the ground; the contaminants migrate to the respective electrodes in a process of separation (ALSHAWABKEH; YEUNG, BRICKA, 1999).

The present work is a scientific review about the application of techniques, such as vitrification and electrokinetics in soil remediation, presenting aspects such as costs, efficiency, global utility among other details.

\section{Techniques}

Vitrification is a process that permanently captures harmful chemicals in a solid block of glass-like material. This prevents them from leaving the place. Vitrification can be done in situ or ex situ. The technique uses electrical energy to create the heat needed to melt the soil. The electrodes are drilled in the polluted area. An electric current is passed between the electrodes, melting the soil between them. The melt begins near the surface of the soil and moves downward. As the soil melts, the electrodes sink even more, making the deeper soil molten as well. When the energy is turned off, the molten soil cools and vitrifies, which means that it turns into a solid block of glasslike material. The electrodes become part of the block. When vitrified, the original volume of the soil decreases. This causes the surface of the soil in the area to be slightly lowered. To level it, the sunken area is filled with clean soil (USEPA, 2001).

According to Bielefeldt (2003), the technique is based on the melting of the soil matrix and subsequent solidification forming a solid block of amorphous vitreous matter. It can performed ex situ in natural gas reactors, where the temperature reaches $1500^{\circ} \mathrm{C}$; or in plasma reactors, where vitrification occurs between 1400 and $1650^{\circ} \mathrm{C}$. In both cases the organic compounds are totally eliminated (BIELEFELDT, 2003).

In situ vitrification uses a system of electrodes, usually of graphite, with $5 \mathrm{~cm}$ of diameter, inserted $60 \mathrm{~cm}$ in the ground, forming a square of $1 \mathrm{~m}$ of edge. The application of electric potential to the electrodes $(25 \mathrm{~kW}$, $13000 \mathrm{~V}$ ) promotes sufficient temperature increase for the fusion of most soil components $\left(1900{ }^{\circ} \mathrm{C}\right)$ (USEPA, 2001; BIELEFELDT, 2003).

According to Neto (2000), initially, the area of soil that will be treated is covered by a superficial layer of graphite and fiberglass that serve to initiate the process. Rectangular graphite electrodes are generally employed and spaced apart maintaining an average distance of 1.7 meters. Once the process is started, the molten soil mass grows vertically from the surface layer and longitudinally towards the center of the area to be treated, from the wall of the electrodes. With the increase of temperature, between 1600 and $2000{ }^{\circ} \mathrm{C}$, the organic materials present in the soils are initially vaporized and later occurs the pyrolysis (opening in absence of oxygen) of its constituent parts. Combustion gases, mostly airborne, move slowly through the molten mass toward the surface. One part can be dissolved in the molten mass and another part can be emitted into the environment after passing through a gas capture and treatment system. The soil is cast at rates of 4 to 6 tons per hour and results in a meltdown of 1 to 2 inches per hour. The final reaction product has great resemblance to vitreous material. While cooling, there is a total volume reduction due to the contraction during solidification.

This technique was widely used in several impacted areas of the United States (Superfunds), with a reduction in soil matrix volume ranging from $20 \%$ to $40 \%$. Its disadvantage is the high cost and the strong emission of gases during the application (PARNELL et al., 2001).

One of the advantages observed in the application of the vitrification technique is the low leaching of the vitreous materials formed during the process. Vitreous materials are slowly leached under the action of water and have a stable structure. This feature reduces the potential for contamination of hazardous elements to the environment, allowing this technique to be very 
suitable for the treatment of hazardous and radioactive materials (NETO, 2000).

After turning off the electricity, the mass cools in the place, forming a monolithic glass with physical and chemical characteristics similar to those of volcanic glass. A gas collecting system is used to process the effluent gas and provide clean emission. This technique is successfully used in soil contaminated with mercury, arsenic, organochlorine pesticides and PCBs. It is also used with radioactive waste. The chemical stability achieved by this method is sufficient to maintain the chemical and physical members for more than one million years (DYMINSKI, 2006).

This technology is most commonly used for immobilization of metals, but associated with vapor extraction techniques can be efficient in the extraction of volatile organic compounds (USEPA, 2001). In this case a cover is installed covering the heated area, collecting the vapors for later treatment. The vitrified block may be left in place definitively; however, periodic sampling should be carried out in the surroundings. This measure increases the level of environmental safety (OSHA, 1993).

The depth of the vitrification technique is limited by the length of the graphite electrodes and by the availability of energy. Pollutants react in various ways to this remediation technique. Organic pollutants are pyrolyzed and are generally reduced in gases. The gases rise to the surface where they are collected by a gas booth for further treatment (BEHM, 1997).

Electrokinetic remediation is an in situ technology that consists in the controlled application of continuous low intensity electric currents (low intensity direct electric current) through two electrodes or more distributed in the soil. The generated electric field moves the contaminant allowing the extraction or separation of the contaminants (MATURI et al. ., 2006).

Furthermore, the electric field mobilizes electrically charged species, particles and ions in the soil by the following processes: Electromigration: Consists of the movement of the ions in the water retained in the soil under the action of an electric field generated between the anode and the cathode. The anions move toward the anode and the cations towards the cathode. Electrophoresis: It is the movement of charged particles in the soil under the action of the electric field. Electroosmosis: consists of the movement of groundwater, or aqueous solution that has been added to promote the movement of pollutants, the liquid typically flows from the anode to the cathode. Electrolysis: a set of reactive processes that happen on anodic and cathodic surfaces placed in the soil, either directly or within an electrolyte solution in contact with the soil (ACAR, ALSHAWABKEH, 1993; LOPEZ-VIZCANO et al., 2012; RODRIGO et al. 2014).

The application can occur alone or in combination with other techniques (SAICHEK; REDDY, 2003; MENA et al., 2015). The processes can be influenced by the use of surfactants or reagents to increase the rate of removal of the contaminants in the electrodes, these and other details of the technique have already been addressed in other works (BRAGATO, 2006; DOS SANTOS, 2015).

One of the most important advantages of the technology is the effectiveness for the treatment of soils of low hydraulic permeability, where other techniques of natural or traditional attenuation are not suitable. In contrast, as a consequence of the process, the water's oxidation forms an acidic front resulting from $\mathrm{H}+$ ions that moves towards the cathode mainly by electromigration, thus releasing the fixed pollutants in the soil. The reduction of the water at the cathodic surface generates a basic front opposite to the acid, due to the formation of $\mathrm{OH}$ - ions, both fronts can be modified by the addition of reagents (DOS SANTOS, 2015).

The first records of use of the technique are from 1939. The former Soviet Union was the pioneer, in 1970 , of the use of the technique for extraction of concentrated metals in the soil and to explore the deep minerals. In the mid-1980s, the methodology became a solution for contaminated soils, since then several researchers and companies started to use the technique (EPA, 2004).

In 1995 Geokinetics International Inc. obtained a patent for the electrokinetic process. The methodology controlled the electrolytic $\mathrm{pH}$ and electrolyte levels on the electrode with the use of additives to dissolve the contaminants; the estimated cost for this company was $\$ 200$ to $\$ 325 / \mathrm{m} 3$ per year (EPA, 1997). Over the years, more companies entered the field and other patents were developed assisted by research institutions.

In situ experiments demonstrated the efficiency and applicability of the technique, Jackman et al. (2001) evaluated the methodology in a silt soil contaminated with $811 \mathrm{mg} / \mathrm{kg}$ of dry soil with 2,4 dichlorophenoxyacetic acid, the soil compartment was $22 \mathrm{~cm}$ long, $7 \mathrm{~cm}$ wide and $4 \mathrm{~cm}$ deep. A carbon felt anode and stainless steel cathode were used at an applied current density of $0.89 \mathrm{~A} / \mathrm{m} 2$. The pollutant moved towards the cathode and the removal efficiency was $87.1 \%$.

Another study evaluated the performance of the treatment and cost analysis of the electrokinetic process for the oxidation of trichlorethylene, using an electric gradient of $1 \mathrm{~V} / \mathrm{cm}$ and a treatment time of 10 days. The results show that the graphite electrodes are superior to stainless steel electrodes, that in sandy soils the process is less efficient than in a clayey soil showing that the performance is related to the permeability and that the costs of the process can be low if they are adopted appropriate operating conditions (YANG; LIU, 2001).

The technique was also used for separation of perchlorethylene in a sandy soil, the voltage gradient was controlled at $1 \mathrm{~V} / \mathrm{cm}$ and the efficiency reached $90 \%$ after a treatment of 10 days (CHANG; CHENG, 2006). The application of electrokinetics for the remediation of contaminated soils in situ proved to be an efficient process for the extraction of different contaminants. Table 1 below presents a comparison between the techniques presented. 
Table 1 - Comparison between vitrification and electrokinetic techniques

\begin{tabular}{|c|c|c|}
\hline & Vitrification & Electrokinetic \\
\hline Application & $\begin{array}{l}\text { Ex situ } \\
\text { In situ }\end{array}$ & In situ \\
\hline Advantages & $\begin{array}{l}\text { Low leaching } \\
\text { Reduction of soil volume } \\
\text { Reuse of vitrified material } \\
\text { Agility and precision }\end{array}$ & $\begin{array}{l}\text { Occur with other techniques } \\
\text { Surfactants or reagents increase efficiency } \\
\text { Low cost } \\
\text { Low energy demand }\end{array}$ \\
\hline Disadvantages & $\begin{array}{c}\text { Emission of gases } \\
\text { Limited application depth } \\
\text { High cost }\end{array}$ & $\begin{array}{l}\text { Formation of acidic front and basic front } \\
\text { Lower efficiency }\end{array}$ \\
\hline Efficiency & $95-99,9 \%$ & $85-95,0 \%$ \\
\hline Costs & High & Low \\
\hline Indications & $\begin{array}{l}\text { Hazardous and radioactive } \\
\text { materials } \\
\text { Immobilization of metals }\end{array}$ & $\begin{array}{l}\text { Hazardous and radioactive materials } \\
\text { Low permeability soils }\end{array}$ \\
\hline
\end{tabular}

\section{Conclusions}

Given the variety of methods and techniques of soil remediation that exist today, this bibliographical review had as main objective to approach the techniques of vitrification and electrokinetics in soil remediation. This review does not intend to exhaust the subject, but to know the principles, forms of application, advantages and disadvantages, efficiency, costs and application of the methods most cited in the literature.

In this context, the techniques presented here proved to be effective for the application in various soils and pollutants. Contaminant immobilization techniques are commonly proposed to avoid the free circulation of soil residues. Vitrification, for example, can be efficient for remediation of various types of chemicals in soils. Some advantages in the application of the technique can be observed, such as: On-site application, low pollutant release, soil volume reduction, re-use of vitrified material, agility and precision.

When used properly, vitrification can be fairly safe, however wet soil should be dried first to avoid formation of vapors that may compromise the effectiveness of the technique. The vitrified block that is left in place is permanent and not harmful to people and the environment.

Regarding the costs, the electrokinetic technique proved to be more economically viable than the vitrification method, although some parameters must be analyzed prior to the application of the technique in order to estimate the costs. Furthermore, electrokinetics has been shown to be a very efficient technique and is used in low permeability soils, the electrokinetics are usually linked to other techniques for total removal of contaminants.

\section{References}

ACAR YB, ALSHAWABKEH AN. Principles of electrokinetic remediation. Environ. Sci. Technol. 1993;27:2638-2647.

ALSHAWABKEH AN, YEUNG AT, BRICKA MR. Practical aspects of in-situ electrochemical extraction. J. Environm. Eng. 1999;125:27-35.

BEHM E, GROSS M, QUESENBERRY D, VIPPERMAN D. In situ vitrification. Civil Engineering Dept, Virginia Tech, 1997.

BIELEFELDT AR. Stabilization and Solidification. Reading Notes. University of Colorado at Boulder, 2003.

BRAGATO M, TENÓRIO JAS. In-situ Chemical Oxidation of Soil Contaminated by Benzene, Lead and. Extraction, Processing, Structure and Properties Proceedings. Warrendale. Orlando: 2007.

BRASIL. Ministério do Meio Ambiente. CONAMA no 420. Resolução no ${ }^{2} 20.28$ de dezembro de 2009.

CHANG JH, CHENG SF. The remediation performance of a specific electrokinetic integrated with zero-valent metals for perchloroethylene contaminated soils. Journal of Hazourdous Materials. 2006;131:153-162.

DOS SANTOS EV. Aplicação de tratamentos eletroquímicos integrados para remediação de solos e águas contaminadas com petróleo e pesticidas [thesis]. Natal: Universidade Federal do Rio Grande do Norte; 2015. 140 p. 
DYMINSKI AS. Contaminação de solos e águas subterrâneas. 1st ed. UFPR; 2006.

FONINI A, ROJAS JWJ. Técnicas empregadas na remediação de solos contaminados. Associação Brasileira de Mecânica dos Solos e Engenharia Geotécnica. Anais II Geojovem [Internet]. 2017 [cited 2018 jul 09]. Available from: https://www.abms.com.br/links/bibliotecavirtual/ IIgeojovem2006/2006-fonini-rojas.pdf.

HU N, LI Z, HUANG P, TAO C. Distribuition and mobility of metals in agricultural soils near a copper smelter in South China. Environmental Geochemistry and Health. 2006;28:19-26.

JACKMAN SA, MAINI G, SHARMAN KA, SUNDERLAND G, KNOWLES JC. Electrokinetic movement and biodegradation of 2,4-Dichlorophenoxyacetic acid in silt soil. Biotechnology and Bioengineering. 2001;74:40-48.

LIU L, HAO RX, CHENG SY, GUO HC. Na Integrated Fe asibility Study on Designing Remediation Systems for Petroleum-Contaminated Sites: Water, Air, and Soil Pollution. 2004;156:83-95.

LOPEZ-VIZCAINO R, SAEZ C, CANIZARES P, RODRIGO MA. Electro coagulation of the effluents from surfactanaided soil-remediation processes. Separation and Purification Technology. 2012;98:88-93.

MATURI K, REDDY KR. Simultaneous removal of organic compounds and heavy metals from soils by electrokinetic remediation with a modified cyclodextrin. Chemosphere. 2006;63:1022-1031.

MEEGODA J, EZELDIN SA, FANG HY, INYANG $\mathrm{H}$. Waste Immobilization Technologies. Practice Periodical of Hazardous, Toxic, and Radioactive Waste Management. 2003;07:1-13.

MENA E, RUIZ C, VILLASENOR J, RODRIGO MA, CANIZARES P. Biological permeable reactive barries coupled with electrokinetic soil flushing for the treatment of diesel-polluted clay soil. Journal of Hazardous Materials. 2015; 283:131-139.

NETO FAO, SANTOS PRP, GOMES GLGC. Considerações sobre tecnologias para remediação de solos e águas subterrâneas contaminadas e suas aplicações em polos industriais na região metropolitana de Salvador e na antiga Fábrica da COBRAC em Santo Amaro-BA [monography]. São Paulo: Escola Politécnica/USP; 2000.

OSHA - Occupational Safety \& Health Administration [Internet]. United States: Department of Labor, Epa/Labor Superfund Health \& Safety Task Force [cited 1993 jun 28]. Osha Audits Of Superfund Sites From 1993 To 1993. Toxic and Hazardous Substances/Air contaminants 1997. [cited 2018 jul 09]. Available from: http://www.osha.gov/ SLTC/hazardouswaste/sftaskrpt.html
PARNELL GS, FRIMPON M, BARNES J, KLOEBER JRJM, DECKRO RF, JACKSON JA. Safety Risk Analysis of an Innovative Environmental Technology. Risk Analysis. 2001;21:143-155.

RODRIGO MA, OTURAN N, OTURAN MA. Electrochemically Assisted Remediation of Pesticides in Soils and Water: A review. Chemical Reviews. 2014;114:8720-8745.

SAICHEK RE, REDDY KR. Effect of pH control at the anode for the electrokinetic removal of phenanthrene from kaolin soil. Chemosphere. 2003;51:273-287.

EPA - Environmental Protection Agency. United States: Environmental Protection Agency under EPA, FRTR (Federal Remediation Technologies Roundtable). Abstracts of Remediation Case Studies and Technology Assessment - fact sheet. 2004;8:1-12.

USEPA - U.S. Environmental Protection Agency [Internet]. A Citizen's Guide to Vitrification. 2001. [cited 2018 jun 09] Available from: www.nepis.epa.gov/Exe/ZyPURL. cgi?Dockey=10002SQR.TXT

USEPA - U.S. Environmental Protection Agency [Internet]. EPA's Cleaning Up the Nation's Waste Sites: Markets and Technology Trends. 2004. [cited 2018 jun 09] Available from: http://www.epa.gov/superfund/accomp/news/30years.htm

YANG GCC, LIU CY. Remediation of TCE contaminated soils by in situ EK-Fenton process. Journal of Hazardous Materials. 2001;85:317-331. 